\title{
Description of new sour cherry cultivars and cultivar candidates bred in the Research Institute for the Fruit Growing and Ornamentals
}

\author{
Apostol, J. \\ Research Institute for Development of Fruitgrowing and Ornamentals Ltd., Budapest
}

\section{'Piramis'}

Origin: It is the result of purposeful multiple crosses between varieties as M221 ('Pándy' $\times$ 'Olivet') $\times$ 'Meteor korai' ('Pándy' $x$ 'Nagy angol'). Its technical identity in the nursery was IV-2/152. The breeder is János Apostol.

It is a brevetted cultivar registered by the State since 2004 .

Early ripening fruits are of extra quality, offering firstling crop on the market after having been hand-picked. Its spindle crown form is adapted for closely planted, modern intense orchards.

Around the first days of June, ripe fruits appear 2-4 days earlier than those of the earliest cultivar 'Meteor korai'. Fruit size is large or very large, 24-26 mm, occasionally $30 \mathrm{~mm}$. Similarly to 'Pándy', it is a glass cherry type. Under the glossy skin, the pulp is deep red, the juice is medium dyeing. Its taste is sour-sweet, balanced as expected for a sour cherry. The flesh is medium firm as of the 'Pandy'. The stone is medium (7-8\% of the volume). The stem is medium long, $38-42 \mathrm{~mm}$. At full maturity, the fruit is detached dry from the peduncle. Bracts at the base of the stems are absent. Ripe fruits may remain on the tree for 2-3 weeks without loss of quality. The acids are maintained even beyond the beginning of dehydration.

The tree is medium vigorous, the few braches are erect and are loaded with short spears over their whole length, which is like at 'Meteor korai', they do not tend to bifurcate after years. The crop is grown on the spears, therefore the branches do not get bald.

The self fertility of the flowers promises a fruit set up to 5-8 per cent only, therefore pollen sources ought to be available in the near proximity.

Cultivars as efficient pollinisers are registered as 'Katalin', 'Carmen', 'Germersdorfi 3', 'Linda', 'Aida and 'Margit' sweet cherries.

The special crown form proper of this cultivar (the original seedling developed on its own root a canopy at the

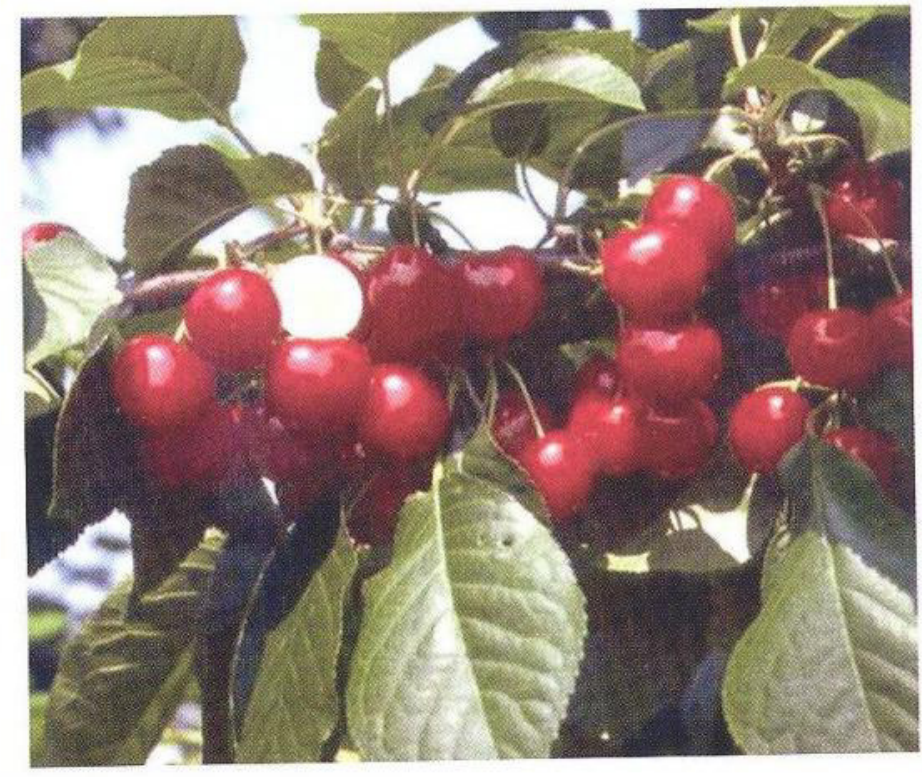

'Piramis'

age of 25 years of only $140 \mathrm{~cm}$ diameter) allows high densities in the plantations up to 2500-3000 trees per ha, either on dwarfing understocks or even on Prunus mahaleb without pruning, moreover, to orchards designed for hand picking fruits of extra quality.

Its susceptibility to Monilia shoot necrosis and to Blumeriella leaf spot is low (mediocre).

\section{DU-1 ('Ducat')}

It is a seedling of unknown, open pollinated parents spotted on the site of its origin. Its author is János Apostol.

Early ripening, primeur type cultivar candidate with high (extra) quality fruit intended also to be hand-picked for fresh consumption.

The time of maturity is very early, around 15-20 May. The $22-24 \mathrm{~mm}$ fruits' volume is $5-6 \mathrm{~g}$. The form is round, 
slightly flattened at the peduncular end. The colour is dark carmine red, the skin is glossy, the taste is sweet or soursweet, balanced agreeable for being sour cherry. The pulp is medium firm, the stone is intermediate, i.e. $6-7 \%$ of the volume. Fruit stem is of medium length, $38 \mathrm{~mm}$ as a mean. Yields are regular and copious on the site of origin.

The tree is of medium vigour, the majority of fruit is set on the short spears, therefore the tendency of getting bald on the branches is low.

The blooming period is intermediate and the autoincompatible flowers need alien pollinisers. The search for the best cultivars to be associated in the plantations is in progress. Recent data indicate the sweet cherry cultivars 'Paulus', 'Carmen' and 'Katalin' to be recommended with high probability.

The most advantage of the cultivar is its high quality for fresh consumption in the earliest cherry season.

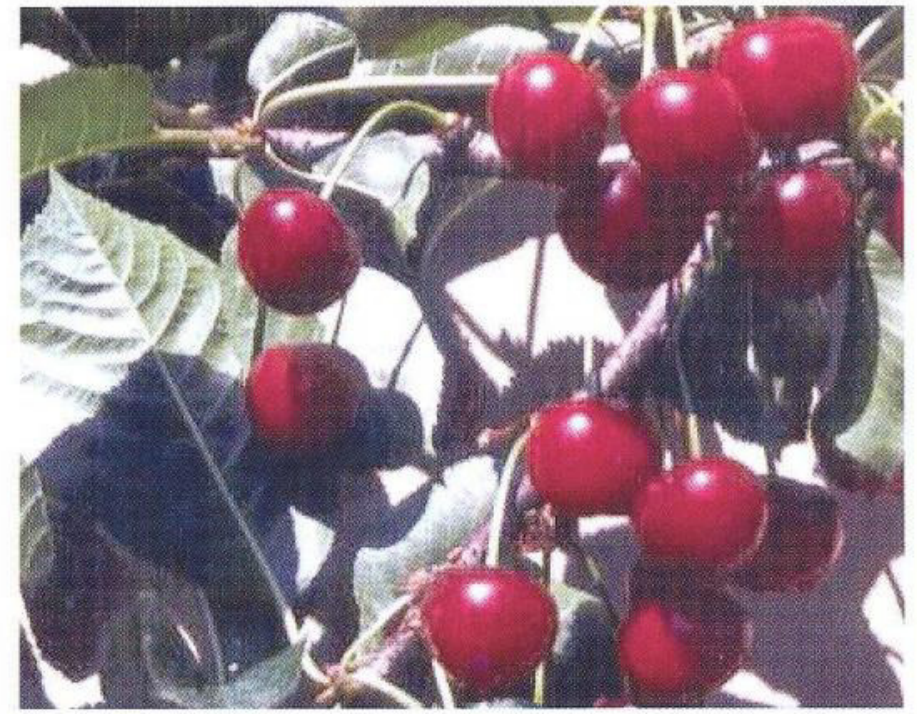

Du-1 ('Ducat') 